\title{
Wild-derived mouse stocks: an underappreciated tool for aging research
}

\author{
James M. Harper
}

Received: 10 April 2008 / Accepted: 14 April 2008 / Published online: 30 May 2008

(C) American Aging Association 2008

\begin{abstract}
Virtually all biomedical research makes use of a relatively small pool of laboratory-adapted, inbred, isogenic stocks of mice. Although the advantages of these models are many, there are a number of disadvantages as well. When studying a multifaceted process such as aging, the problems associated with using laboratory stocks are greatly inflated. On the other hand, wild-derived mouse stocks, loosely defined here as either wild-caught individuals or the recent progeny of wild-caught individuals, have much to offer to biogerontology research. Hence, the aims of this review are threefold: (1) to (re)acquaint readers with the pros and cons of using a typical inbred laboratory mouse model for aging research; (2) to reintroduce the notion of using wild-derived mouse stocks in aging research as championed by Austad, Miller and others for more than a decade, and (3) to provide an overview of recent advances in biogerontology using wildderived mouse stocks.
\end{abstract}

Keywords Aging · Inbred - Laboratory mouse . Lifespan $\cdot$ Wild-derived

J. M. Harper

Department of Pathology and Geriatrics Center, University of Michigan School of Medicine,

Ann Arbor, MI 48109, USA

J. M. Harper $(\bowtie)$

109 Zina Pitcher P1., Room 3005 BSRB,

Ann Arbor, MI 48109-2200, USA

e-mail: jmharper@umich.edu

\author{
Abbreviations \\ CBG Corticosteroid binding globulin \\ CR Caloric restriction \\ DC Diversity control \\ GC Glucocorticoid \\ GH/IGF Growth hormone/insulin-like growth \\ factor \\ Ghrhr Growth hormone releasing hormone \\ receptor \\ GHRKO Growth hormone receptor knockout \\ GR Glucocorticoid receptor \\ HPA Hypothalamic-pituitary-adrenal \\ HPG Hypothalamic-pituitary-gonadal \\ IGF-1R Insulin-like growth factor I receptor \\ IGFBP Insulin-like growth factor binding protein \\ IR Insulin receptor \\ Id Idaho mouse stock \\ Ma Majuro mouse stock \\ MuLV Murine leukemia virus \\ PAPP-A Pregnancy associated plasma protein A \\ SPF Specific pathogen free \\ Surf1 Surfeit locus protein 1
}

\section{Why use wild-derived mice in aging research?}

The notion that the standard laboratory mouse may not be an ideal model for aging research is not new (Austad 1993a, b; Miller and Nadon 2000; Miller et al. 1999). Nonetheless, the biogerontologist's attitude 
toward using inbred laboratory stocks has changed little, and these animals are still the workhorses of modern aging research. In this review I will briefly review the advantages and disadvantages of using laboratory inbred versus wild-derived mouse stocks for aging research, as well as providing a synopsis of recent findings concerning aging and lifespan in wildderived mouse stocks.

\section{The laboratory mouse: the good, the bad, and the ugly}

The good

Most laboratory stocks of the house mouse (Mus musculus) have been around for decades, providing a rich body of knowledge regarding their husbandry, as well as information on their development, reproduction, physiology, behavior, and-now more important then ever-their genetics. Other advantages include the fact that commonly used mouse stocks are docile, specific pathogen free (SPF), readily available from multiple commercial sources, are relatively cheap, and are familiar to the biomedical research community.

Another advantage of most laboratory mouse stocks is that all individuals of a given line are virtually genetically identical, due to tens-to-hundreds of generations of inbreeding (i.e., brother-sister matings), and they are more or less homozygous at all genetic loci (with the exception of F1 hybrids derived as the product of mating two different inbred stocks; these will be heterozygous at all loci that happen to differ between the parental strains). As a consequence, there are major advantages to using laboratory stocks for specific types of research, as outlined by Miller et al. (1999), and their use will undoubtedly continue to make important contributions to biomedical science.

The bad

The fact that inbred mice are genetically identical and homozygous at essentially all loci is not genetically "normal," or representative of humans and other freeliving animal populations and this translates into a number of disadvantages for aging research (Miller et al. 1999). Briefly: (1) each stock represents a single genetic identity, rather than a normal, outbred popula- tion; (2) many stocks possess very rare combinations of homozygous alleles capable of producing viable (and fertile) individuals, a rather atypical condition for natural populations where selection has filtered out these abnormal genotypes; and (3) all laboratory rodent stocks are the end-product of tremendous selection pressures for successful propagation under laboratory conditions. Of these attributes, the first is perhaps the most relevant because it is impossible to know whether research findings pertaining to a specific inbred stock translates to all of mousedom, or whether it is simply a consequence of the unique genetic identity of that stock. Also note that, while F1 hybrid stocks do not harbor the same degree of genetic homozygosity (because the alleles fixed at specific loci will often differ between the parental strains), and hence are often the better choice, all individuals are still genetically uniform.

The ugly

Many inbred stocks carry mutations whose effects make them unsuitable for aging research. For example, $\mathrm{C} 3 \mathrm{H}$ mice go blind within the first few months of life (Chang et al. 2002), and DBA mice go deaf (Zheng et al. 1999) and develop an eye disorder called pigmentary glaucoma (Wong and Brown 2007) within a year of being born. Clearly, neither of these models would be particularly useful for assessing agingrelated changes in performance on behavioral tasks involving visual and/or auditory cues. What's more, dramatic differences for a given trait may exist even between closely related substrains. Continuing with the hearing example, some substrains of 129 mice, the most common source of embryonic stem cell lines used for gene targeting studies, exhibit marked hearing loss early in life, while others show little or no impairment over the same period (Johnson et al. 2006). Interestingly, the pattern of age-related spiral ganglion cell degeneration in wild caught mice suggests that the pattern typically seen in laboratory stocks significantly deviates from the norm (Dazert et al. 1996). Finally, significant differences between laboratory stocks with regard to rates of thymic involution (Hsu et al. 2005), age-related changes in metabolism (Goren et al. 2004; Murray et al. 1993), and a variety of behavioral and neural parameters (Ingram and Jucker 1999) have been described, and it is likely that differences exist for a number of additional measures as well. 
Aging is a multifaceted process characterized by the progressive, and more or less parallel, decline of multiple physiological systems with time. Moreover, multiple age-related pathologies usually manifest themselves in a typical aging population. That is, some individuals die of heart disease, some die of cancer, and some die of diabetic kidney failure. Unfortunately, a number of laboratory stocks deviate from this pattern in that they develop, and may ultimately succumb to, what can be thought of as line-specific pathologies (Miller and Nadon 2000). Clearly, this limits one's ability to generalize about the effectiveness of an anti-aging intervention when it may simply be a reflection of how that intervention interferes with the onset and progression of, for example, thymic lymphoma in $\mathrm{AKR} / \mathrm{J}$ mice or pulmonary adenoma in $\mathrm{A} / \mathrm{He}$ mice (Miller and Nadon 2000); although it is notable that caloric restriction (CR) slows the onset and progression of virtually every age-related pathology (Masoro 2005).

\section{Wild-derived mouse stocks: pros and cons}

\section{The pros}

By and large the primary advantage to using a wildderived stock is that the population is composed of genetically heterogeneous individuals (although proper collection and husbandry practices are needed to ensure this state) whose genetic repertoire has been shaped by "real world" conditions. This is in stark contrast to a standard laboratory stock, which may be important for the reasons outlined above. However, another, often overlooked, consequence of creating laboratory stocks is the loss of naturally occurring alleles that may act to slow the aging process, among other things (Harper et al. 2006a; Miller et al. 2000a, b). For example, in a study of feral house mice, Gardner (1993) identified an allele involved in resistance to murine leukemia virus (MuLV) that had never been described in laboratory mice. Hence, by studying wild-derived populations, biogerontologists may also (re)discover key alleles involved in the regulation of aging.

The cons

The most obvious disadvantage to using wild-derived mouse stocks is that the progenitor mice are derived from populations living in barns, sheds or similar habitats not long ago. That is, they need to be livetrapped and transported to an animal facility for breeding and/or the eventual testing for the trait(s) of interest. And, because wild-derived lines are not maintained by commercial breeders, they are much less familiar to biomedical science.

In addition, real-world mice come with real-world parasites, viruses and bacteria. Consequently, those in charge of SPF animal facilities are justifiably apprehensive about letting these "dirty" animals in. However, with the proper resources, some time and, admittedly, expense, wild-caught animals can be made SPF (Miller et al. 2000a, b) and will remain SPF if standard husbandry practices are employed.

Moreover, one cannot discount the influence of maternal effects on wild-caught individuals and their immediate offspring. For example, fluctuations in maternal nutrition, a very pertinent issue for free-living populations, has marked effects on the growth and development of a female's offspring, effects which can persist for several generations (Liang et al. 2007). The timing of fluctuation in maternal nutrition (e.g. pregnancy versus lactation) is also important in that the specific effects on the offspring can vary (MartinGronert and Ozanne 2006). In addition to nutritional variation, other types of maternal stress (e.g., social stress) can also have lasting effects upon their offspring (Dioro and Meany 2007). Hence, it may be necessary to monitor a captive population for several generations prior to conducting the actual study, either to document a lack of maternal effects or to ensure a "wash-out" of these effects. However, note that maternal effects are relevant to laboratory-derived populations as well (Dioro and Meany 2007).

Finally, although they may be content to spend their lives in the comparatively plush environment of the shoebox cage, many wild-caught individuals simply do not reproduce well in captivity. Hence, a large founder population is needed to ensure enough progeny for study, as well as providing for future generations while preserving genetic heterogeneity; but note that some genetic heterogeneity is lost which each successive generation, regardless of the husbandry scheme employed. In fact, in a closed population wild-derived mice are sure to become something very similar to a domesticated laboratory stock given enough time unless steps are taken to maintain and/or monitor the heterogeneity of the population; 
for example mitochondrial genome sequencing in conjunction with the periodic introduction of new breeding stock, or the generation of a completely new stock every few years. Obviously, this makes it significantly more expensive to establish and maintain a captive wild-derived population relative to a laboratory stock.

\section{The truth about MOLF, CAST, and their ilk}

One often sees references to "wild-derived" mouse stocks in the literature (Bektas et al. 2004; Klebanov et al. 2001; Roberts et al. 2007), and just as purported outbred mouse lines are offered by commercial breeders, so too are wild-derived stocks; e.g., the $\mathrm{MOLF} / \mathrm{Ei}$ and CAST/Ei. Unfortunately, similar to the so-called outbred mouse lines (Miller et al. 1999), a close examination of the history of these wild-derived lines reveals that this distinction is dubious.

In particular, although these stocks were somewhat recently derived from wild-caught individuals (but note that all laboratory stocks are the descendants of wild-caught individuals), and they are often not of the European domesticus subspecies group (Yoshiki and Moriwaki 2006), they are still the product of multiple generations of brother-sister matings in the presence of captive housing conditions. Thus, even though they were inbred prior to being domesticated, which may mean that "wild" alleles have been maintained within the population (Klebanov et al. 2001), these stocks are still highly inbred and carry the same baggage as other inbred stocks. Hence, I feel it is more correct to refer to them as "genetic deviants" rather than true wild-derived stocks.

Of course, this leads to the question of how exactly one defines a wild-derived mouse stock. Unfortunately, no formal definition exists. Undoubtedly, wild-caught individuals, or the recent progeny of wild-caught individuals (e.g., offspring or grandoffspring), constitute wild-derived stocks, but for later generations it becomes more muddled. However, if the wild-derived state is defined by reference to specific, easily measured phenotypic 'benchmarks' already shown to be different in the wild-derived versus laboratory populations, then it could be argued that no significant deviation from these benchmarks with time is indicative of maintained wild-derived status. In the end, it is up to the individual investigator to decide.

\section{Wild-derived mouse stocks are very different from laboratory stocks}

I have argued that laboratory mice are odd and are expected be different from wild-derived stocks in a number of ways, and that these differences could be a hindrance to examining fundamental questions in the biology of aging. Below, I review available physiological data for wild-derived mouse stocks maintained in captivity, as well as reviewing the significance of these findings in the context of biogerontology. Most of the data are from studies using two mouse stocks derived from wild progenitors live-trapped in either North-Central Idaho ("Id" mice) or the South Pacific Island of Majuro ("Ma" mice) as described in (Miller et al. 2000a, b); although data from other study populations are included when available.

\section{Lifespan}

Are wild-derived mouse stocks long-lived relative to their inbred counterparts? Unfortunately, the answer is not simple. In two separate lifespan studies, Miller et al. demonstrated that both the second (Miller et al. 2002a) and fifth (Harper et al. 2006a) captive-born generations of Id and Ma mice were significantly longer-lived than a "diversity control" (DC) stock with equal genetic contributions from the laboratoryinbred strains $\mathrm{BALB} / \mathrm{cJ}, \mathrm{C} 57 \mathrm{BL} / 6 \mathrm{~J}, \mathrm{C} 3 \mathrm{H} / \mathrm{HeJ}$, and $\mathrm{DBA} / 2 \mathrm{~J}$. However, other stocks derived from progenitors live-trapped on two additional South Pacific islands failed to show a difference in lifespan (Miller et al. 2002a; J.M. Harper, R. Miller et al., unpublished). Currently, it is not clear why this is so, although founder effects seem like a reasonable cause.

To the best of my knowledge, these are the only complete lifespan studies that have been done using wild-derived mouse stocks under SPF conditions, but it is interesting that the life table of a second, unique population of Id mice maintained under conventional colony conditions closely resembles that of the SPF Id populations (Harper et al. 2006b). In addition, examination of the survival curves clearly illustrates that the degree of "lifespan extension" seen in each of these wild derived stocks is rather substantial, and provides a point of comparison to nutritional (i.e., $\mathrm{CR}$ ) and genetic models of extended longevity. In particular, maximum lifespan is roughly $20 \%$ greater in the wild-derived stocks, which is about half of that 
seen with CR (Weindruch and Walford 1988) or in Ames and Snell dwarf mice and growth hormone receptor knockout (GHRKO) mice (Brown-Borg et al. 1996; Coschigano et al. 2000), but is similar to that seen with changes in genes for growth hormone releasing hormone receptor (Ghrhr), insulin receptor (IR), insulin-like growth factor I receptor (IGF-1R), pregnancy associated plasma protein A (PAPP-A), and Surfeit locus protein 1 (Surf1) (Flurkey et al. 2001; Bluher et al. 2003; Holzenberger et al. 2003; Conover and Bale 2007; Dell'Agnello et al. 2007). Notably, however, these wild-derived stocks were not exposed to any experimental treatment with a presumptive effect on lifespan, and the longest-lived mouse (an Id female) reached the remarkable age of 4.1 years.

\section{Growth and reproduction}

The selection pressures imposed by laboratory adaptation and selective breeding favor those mice that reproduce the most rapidly and efficiently. Hence, mice that have the largest litters at the earliest age will be the most successful. It is not surprising then, that relative to laboratory-adapted stocks, female wild-derived mice are slower to reach sexual maturity and have significantly smaller litters. This was first shown by Bronson (1984) over 20 years ago, and again by Miller et al. using the Id and Ma stocks described above (Harper et al. 2006a; Miller et al. 2000a, b, 2002a). Moreover, since female body mass and litter size are positively correlated in mice (Roberts 1981), one would predict that laboratory adapted mice would be significantly larger and grow more rapidly than wild-derived mice. This is indeed the case, and is true for both males and females (Bronson 1984; Miller et al. 2000a, b). Notably, these differences in growth and reproduction persist through multiple captive-born generations, indicating that a genetic, and not a nutritional, mechanism underlies this effect. Captive populations of wild rats also exhibit these trends when compared to laboratory rat strains (Clark and Price 1981).

Why is this important? First, there are theoretical reasons to believe that delayed reproduction and reduced litter size will slow aging (Rose et al. 2007), as illustrated by directed selection studies using Drosophila (Hutchinson et al. 1991; Hutchinson and Rose 1991) and in natural populations of guppies (Reznick et al. 2001). Likewise, there are reasons to believe that rapid growth would have deleterious effects on lifespan (Metcalfe and Monaghan 2003). Indeed, within species, small size portends long life, whether it be among breeds of dogs (Greer et al. 2007; Patronek et al. 1997), stocks of flies (Hillesheim and Stearns 1992), stocks of mice (Miller et al. 2000a, b), or within a population of genetically heterogeneous mice (Harper et al. 2004; Miller et al. 2002b).

Presumably, wild-derived stocks are also dramatically different with regard to their reproductive physiology, which could be important in the regulation of life history traits and the aging process. Indeed, Flurkey et al. (2007) documented that females of a stock recently derived from live-trapped progenitors exhibit an extended reproductive lifespan and greater reproductive potential at later ages relative to a number of other laboratory stocks. Yet there seems to be nothing known regarding uterine biology or the hypothalamic-pituitary-gonadal (HPG) axis of wild-derived stocks, although studies in other rodent species have documented significant changes in these systems in domesticated versus wild populations (Blottner and Stuermer 2006; Blottner et al. 2000; Künzl et al. 2003; Kunzl and Sachser 1999; Stuermer et al. 2006).

\section{Endocrinology}

Although the role of specific hormones in the aging process is still contentious, there is no doubt that they are important mediators of lifespan. By and large, the growth hormone/insulin-like growth factor (GH/IGF) system has garnered the most attention, and there is a substantial body of work linking a reduction in $\mathrm{GH} /$ IGF signaling to increased lifespan in mammals (Bartke et al. 2003). Therefore, it is noteworthy that, relative to DC control mice, wild-derived mouse stocks have significantly lower levels of serum IGF-I early in life, and that serum IGF-I is a significant predictor of lifespan in F2 hybrid crosses between wild-derived and C57BL/6J mice. Moreover, serum IGF-I remains lower until at least early middle age (Harper et al. 2006a). More data on receptor levels and the activity of downstream signaling cascades, as well as regulators of GH secretion (e.g., GHRH, somatostatin, ghrelin) and the bioavailability of IGF-I (e.g., IGFBPs) are needed to better understand the dynamics of the $\mathrm{GH} / \mathrm{IGF}$ axis in these wild-derived stocks.

Basal glucocorticoid (GC) levels, and by extension basal hypothalamic-pituitary-adrenal (HPA) axis activity, are consistently elevated in wild-derived stocks 
(Harper et al. 2006a; Miller et al. 2000a, b). CR upregulates basal HPA axis activity in rodents, and it has been postulated that this increase in activity may, at least in part, contribute directly to the anti-aging effects of CR (Leakey et al. 1994; Masoro 2007). However, the degree to which HPA activity differs in response to stressors in wild-derived versus laboratory stocks is currently unknown. Moreover, there is nothing known about regulators of GC action, for example corticosteroid binding globulin (CBG) or glucocorticoid receptor (GR) levels, in these mice.

Wild-derived mice also show significant differences in circulating levels of the thyroid hormone thyroxine $\left(\mathrm{T}_{4}\right)$, as well as the fat-derived hormone leptin (Harper et al. 2005, 2006a). These differences are not consistent, however, i.e., wild-derived mice are not always hypothyroid or hypoleptinemic. Moreover, since the role of these hormones in modulating lifespan is contentious; the significance of these findings remains unclear.

\section{Glucose homeostasis}

Improved insulin sensitivity and glucose tolerance are thought to be involved in the life-extending effects of CR (Bartke et al. 2007). However, data from wild-derived mouse stocks challenge the validity of this argument. Specifically, Harper et al. (2005) showed that Ma mice are significantly longer-lived than laboratory mice despite being hyperglycemic, having a higher index of glycation, performing poorly in an intraperitoneal glucose tolerance test, and having presumed pancreatic insufficiency. Meanwhile, long-lived Id mice were statistically indistinguishable from laboratory mice with regard to their glucose balance and insulin sensitivity. While more work needs to be done comparing organspecific insulin signaling pathways in wild versus labderived mouse stocks (Argentino et al. 2005; Dominici et al. 2002, 2003), these data, and a more recent study of GLUT4 transgenic mice (McCarter et al. 2007), suggest that a diminution of blood glucose and indices of glycation may not be a prerequisite for increased lifespan in mice, despite thinking to the contrary (Lee and Cerami 1992).

\section{Cell biology}

Primary fibroblast cell lines derived from the ancestors of wild-caught mice exhibit significant differences in growth and proliferation and are more resistant to changes associated with cellular senescence (Flurkey et al. 2007). In addition, primary fibroblast cell lines from different, unrelated wild-derived stocks are more resistant to a variety of cytotoxic agents and metabolic insults relative to cell lines derived from laboratory mouse stocks (Harper et al. 2007). These data are particularly interesting given the growing body of evidence linking enhanced stress resistance to extended longevity (Murakami 2006). At present the mechanistic bases for these differences remain unknown, but telomere biology may be an important mediator of cellular stress resistance (Rubio et al. 2004) and inbreeding has been shown to significantly alter telomere length in rodents (Hemann and Greider 2000; Manning et al. 2002). In addition, significant differences in membrane fatty acid composition between wild-derived and laboratory mouse stocks (Hulbert et al. 2006) may mediate the susceptibility of cellular membranes to peroxidation (Hulbert et al. 2007), although there are no differences in free radical production by isolated heart mitochondria in wildderived versus laboratory mice (Lambert et al. 2007).

\section{Calorie restriction}

Laboratory mice are fat, with a body mass index (BMI) almost $50 \%$ greater than that of same-age wild-derived stocks (Harper et al. 2005). Their absolute fat mass is significantly higher as well (Austad and Kristan 2003) and, not surprisingly, laboratory mice eat more than wild-derived stocks under captive conditions (Austad and Kristan 2003). Thus, it may be that the lifeextending effect of $\mathrm{CR}$ in laboratory rodents (and perhaps all domesticated species) is an artifact of the domestication process whereby overfeeding goes hand-in-hand with increased fecundity. Fortunately, wild-derived stocks provide us with an excellent tool to test this hypothesis (Harper et al. 2006b).

First and second captive-born generations of male house mice exhibit changes in GC and testosterone levels reminiscent of those seen in studies using laboratory strains. Also important, cancer incidence was significantly reduced in CR wild-derived mice, consistent with studies using other rodent models (Patel et al. 2004). Unexpectedly, however, there was no statistically significant effect of CR on mean lifespan; although the six longest-lived individuals in this study were calorically restricted and there was a difference in 
the mortality rate doubling time of CR versus control mice. Hence, it is plausible that animals not selected under laboratory conditions (i.e., not domesticated) fail to show the typical CR effect.

On the other hand, these data also raise the possibility that CR-responsive alleles exist in natural populations, and that these alleles have been inadvertently selected for during domestication. In fact, even in laboratory mice, there is genetic variability for physiologic correlates of the CR effect (Rikke et al. 2003, 2004). By using segregating populations of (wild-derived x laboratory) F2 hybrids, we may be able to find these, and other, genes that are important regulators of mammalian lifespan.

\section{Wild-derived $\mathrm{x}$ laboratory hybrid stocks: a source of unknown aging genes?}

As we have seen, there can be dramatic phenotypic differences between wild-derived and laboratory stocks, especially with regard to growth, reproduction, and lifespan. At least some, if not all, of these differences are the result of underlying genetic variation, which can be quite substantial even among 'typical' laboratory mouse strains (Chia et al. 2005). However, although inter-strain comparisons (e.g., wild-derived versus laboratory stocks) can indicate whether differences in the traits of interests could be due to genetic variation, they tell us very little about which genes are responsible. Alternatively, comparing a hybrid strain to each of its parental strains allows us to address whether genetically based differences exist and if they are the result of additive allelic effects or are simply the result of directional dominance or epistatic interactions. If reciprocal crosses are made [i.e., (wild-derived female x laboratory male) vs (laboratory female x wild-derived male)] we can assess whether maternal effects are important as well.

Using this approach, Dohm et al. (1994) showed that measures of physical activity and endurance in (wild-derived x laboratory) F1 stocks more closely resemble those in the wild-derived parental strain, suggesting that the wild-derived alleles were dominant to the laboratory alleles. This could be a consequence of relaxed selection in the laboratory setting, where foraging, dispersal, and/or escape behavior is not a critical component of everyday life. Meanwhile, in the context of aging, Flurkey et al. (2007) showed marked heterosis for female reproductive lifespan in a (wild-derived x C57BL/6J) F1 hybrid stock, presumably due to the unmasking of alleles for delayed reproductive senescence as a result of out-crossing. Lastly, rate of maturation, body size, hormones, and longevity were evaluated in two [wild-derived (Id or Ma) x C57BL6/J] F2 hybrid mouse stocks, and it was found that the level of nearly all traits, including lifespan, was intermediate to those in the parental stocks, which suggests these traits are modulated by co-dominant loci that distinguish wild-derived from laboratory mice. The next challenge is to identify the specific alleles involved in each of these studies using conventional gene mapping studies.

Furthermore, despite their widely divergent phenotypes, simple inter-strain comparisons between wildderived and laboratory mice do not directly address whether differences between traits of interest, for example body weight and lifespan, represents a coincidence or is the outcome of a set of causal relationships based upon pleiotropic effects of polymorphic alleles. Instead, the construction of F2 intercross stocks (i.e., by crossing F1 hybrids) is needed since it results in a significant degree of genome reshuffling, thereby producing offspring with variable combinations of alleles (Jansen 2003). And, unlike F1 hybrids, which are heterozygous at all loci (except those that happen to be the same in each of the parental strains), F2 intercross stocks have three possible genotypes for each allele: (1) homozygous for parent A; (2) heterozygous; or (3) homozygous for parent B. In this instance, the co-occurrence of traits in the segregating population is indicative that they are regulated to some degree by common, and potentially genetic, factors.

In the case of wild-derived stocks, superior longevity has been attributed to delayed maturation, low IGF-I levels, and/or altered growth trajectories (Harper et al. 2006a); hence one would predict the cosegregation of these traits with lifespan in a segregating F2 population. And indeed, analysis of two (wild-derived x C57BL6/J)F2 segregating populations indicated that serum IGF-I levels were significant predictors of lifespan in both the IdB6F2 and the MaB6F2 stocks (Harper et al. 2006a). Formal documentation of a genetic basis for the co-occurrence of these traits can be done via a gene mapping study, similar to the approach used by Klebanov et al. 
(2001) using segregating populations of four-way cross mice.

\section{Natural variation in mammalian lifespan: an untapped resource for aging research}

In what has become a seminal study for comparative biogerontologists, Austad (1993a, b) demonstrated that a relatively brief period of adaptation to a lowrisk environment can lead to dramatic alterations in reproductive biology and survival in populations of wild opossums. More recently, studies utilizing natural populations of red deer have documented patterns of senescence and the contribution of the environment and genetics to inter-individual rates of aging (Clutton-Brock and Isvaran 2007; Nussey et al. 2007; Wislon et al. 2007). Using fibroblast cell lines from seven species of wild-trapped rodents and a single species of bat, Harper et al. (2007) saw that longevity was associated with the degree of resistance to cytotoxic and metabolic insults, consistent with the idea that the evolution of long-lived species may require enhanced stress resistance. And we already know that at least some populations of captive, wild-derived mice are significantly long-lived relative to laboratory mice. Finally, the utility of studying natural populations has also been realized by invertebrate biogerontologists (Van Voorhies et al. 2005; Melvin and Ballard 2006). Nonetheless, the number of studies that use wild-derived populations is infinitesimally small relative to publications on aging in laboratory stocks of the "big four" of biogerontology: yeast (Saccharomyces cerevisiae), nematode worms (Caenorhabitis elegans), fruit flies (Drosophila melanogaster) and laboratory mice.

Unfortunately, this emphasis on a handful of inbred laboratory species is rather short-sighted, because, although single-gene mutations and selective breeding can seldom increase lifespan by more than $40 \%$ within rodents, natural selection has produced differences of much greater magnitude, upwards of 10-fold. And the differences are more dramatic if all orders of mammals are included. The problem now is that we still don't know how natural evolutionary processes produce this variation in lifespan, or if long-lived animals from different taxa share common genetic pathways for slow aging.

\section{Future directions and concluding remarks}

Are long-lived, wild-derived mice cognitively intact at later ages than their laboratory counterparts? What about immune function? Are there differences in the onset and progression of specific age-related pathologies? These questions, and many others like them, remain unanswered and are viable areas for future research. Moreover, although we know that (some) wild-derived stocks are long-lived, we still don't know why; but the repeated occurrence of specific phenotypes in wild-derived populations, for example low IGF-I levels or elevated antioxidant defenses, would suggest that a detailed characterization of these pathways could hold the key to lifespan determination. Future studies could take advantage of established wild-derived stocks, such as Id and Ma mice, or more ambitious investigators could establish their own study populations.

In summary, most biomedical research on rodents is conducted in isogenic stocks of mice that have experienced tens-to-hundreds of generations of selective pressure for alleles that lead to high fecundity, rapid growth, excessive food intake, and abnormal behavior, thereby creating experimental animals that differ dramatically from their wild ancestors (Ellegren and Sheldon 2008). In addition to the obvious implications for a number of fields of study, there is reason to believe that this process also leads to experimental subjects that are particularly unsuited for biogerontology because the selective pressures that mold fitness traits early in life are also likely to affect the aging process as a consequence of secondary or pleiotropic effects on gerontologically important factors.

Acknowledgments I would like to thank Donna Holmes, Debbie Kristan and an anonymous reviewer for their critical reading of the manuscript. They made a number of useful suggestions that greatly improved its quality.

\section{References}

Argentino DP, Dominici FP, Munoz MC, Al-Regaiey K, Bartke A, Turyn D (2005) Effects of long-term caloric restriction on glucose homeostasis and on the first steps of the insulin signaling system in skeletal muscle of normal and Ames dwarf (Prop1df/Prop1df) mice. Exp Gerontol 40:27-35

Austad S (1993a) The comparative perspective and choice of animal models in aging research. Aging Clin Exp Res $5: 259-267$ 
Austad SN (1993b) Retarded senescence in an insular population of Virginia opossums (Didelphis virginiana). J Zool 229:695-708

Austad SN, Kristan DM (2003) Are mice calorically restricted in nature? Aging Cell 2:201-207

Bartke A, Chandrashekar V, Dominici F, Turyn D, Kinney B, Steger R, Kopchick JJ (2003) Insulin-like growth factor 1 (IGF-1) and aging: controversies and new insights. Biogerontology 4:1-8

Bartke A, Masternak MM, Al-Regaiey K, Bonkowski M (2007) Effects of dietary restriction on the expression of insulinsignaling-related genes in long-lived mutant mice. Interdiscip Top Gerontol 35:69-82

Bektas A, Schurman SH, Sharov AA, Carter MG, Dietz HC, Francomano CA (2004) Klotho gene variation and expression in 20 inbred mouse strains. Mamm Genome 15:759-767

Blottner S, Stuermer IW (2006) Reproduction of wild Mongolian gerbils bred in the laboratory with respect to generation and season 2. Spermatogenic activity and testicular testosterone concentration. Anim Sci 82:389-395

Blottner S, Franz C, Rohleder M, Zinke O, Stuermer IW (2000) Higher testicular activity in laboratory gerbils compared to wild Mongolian gerbils (Meriones unguiculatus). J Zool 250:461-466

Bluher M, Kahn BB, Kahn CR (2003) Extended longevity in mice lacking the insulin receptor in adipose tissue. Science 299:572-574

Bronson FH (1984) Energy allocation and reproductive development in wild and domestic house mice. Biol Reprod 31:83-88

Brown-Borg HM, Borg KE, Meliska CJ, Bartke A (1996) Dwarf mice and the aging process. Nature 384:33

Chang B, Hawes NL, Hurd RE, Davisson MT, Nusinowitz S, Heckenlively JR (2002) Retinal degeneration mutants in the mouse. Vision Res 42:517-525

Chia R, Achilli F, Festing MFW, Fisher EMC (2005) The origins and uses of mouse outbred stocks. Nat Genet 37:1181-1186

Clark BR, Price EO (1981) Sexual maturation and fecundity of wild and domestic Norway rats (Rattus norvegicus). J Reprod Fertil 63:215-220

Clutton-Brock TH, Isvaran K (2007) Sex differences in ageing in natural populations of vertebrates. Proc R Soc Part B Biol Sci 274:3097-3104

Conover CA, Bale LK (2007) Loss of pregnancy-associated plasma protein A extends lifespan in mice. Aging Cell 6:727-729

Coschigano KT, Clemmons D, Bellush LL, Kopchick JJ (2000) Assessment of growth parameters and lifespan of GHR/BP gene-disrupted mice. Endocrinology 141:2608-2613

Dazert S, Feldman ML, Keithley EM (1996) Cochlear spiral ganglion cell degeneration in wild-caught mice as a function of age. Hearing Res 100:101-106

Dell'Agnello C, Leo S, Agostino A, Szabadkai G, Tiveron C, Zulian A, Prelle A, Roubertoux P, Rizzuto R, Zeviani M (2007) Increased longevity and refractoriness to $\mathrm{Ca} 2+-$ dependent neurodegeneration in Surf1 knockout mice. Hum Mol Genet 16:431-444

Dioro J, Meaney MJ (2007) Maternal programming of defensive responses through sustained effects on gene expression. J Psychiatry Neurosci 32:275-284
Dohm MR, Richardson CS, Garland T Jr (1994) Exercise physiology of wild and random-bred laboratory house mice and their reciprocal hybrids. Am J Physiol Regul Integr Comp Physiol 267:R1098-R1108

Dominici FP, Hauck S, Argentino DP, Bartke A, Turyn D (2002) Increased insulin sensitivity and upregulation of insulin receptor, insulin receptor substrate (IRS)-1 and IRS2 in liver of Ames dwarf mice. J Endocrinol 173: 81-94

Dominici FP, Argentino DP, Bartke A, Turyn D (2003) The dwarf mutation decreases high dose insulin responses in skeletal muscle, the opposite of effects in liver. Mech Ageing Develop 124:819-827

Ellegren H, Sheldon BC (2008) Genetic basis of fitness differences in natural populations. Nature 452:169-175

Flurkey K, Papaconstantinou J, Miller RA, Harrison DE (2001) Lifespan extension and delayed immune and collagen aging in mutant mice with defects in growth hormone production. Proc Natl Acad Sci UA 98:6736-6741

Flurkey K, Brandvain Y, Klebanov S, Austad SN, Miller RA, Yuan R, Harrison DE (2007) PohnB6F1: A cross of wild and domestic mice that is a new model of extended female reproductive lifespan. J Gerontol A Biol Sci Med Sci 62:1187-1198

Gardner M (1993) Genetic control of retroviral disease in aging wild mice. Genetica 91:199-209

Goren HJ, Kulkarni RN, Kahn CR (2004) Glucose homeostasis and tissue transcript content of insulin signaling intermediates in four inbred strains of mice: C57BL/6, C57BLKS/6, DBA/2, and 129X1. Endocrinology 145:3307-3323

Greer KA, Canterberry SC, Murphy KE (2007) Statistical analysis regarding the effects of height and weight on lifespan of the domestic dog. Res Vet Sci 82:208-214

Harper JM, Galecki AT, Burke DT, Miller RA (2004) Body weight, hormones and $\mathrm{T}$ cell subsets as predictors of lifespan in genetically heterogeneous mice. Mech Ageing Develop 125:381-390

Harper JM, Durkee SJ, Smith-Wheelock M, Miller RA (2005) Hyperglycemia, impaired glucose tolerance and elevated glycated hemoglobin levels in a long-lived mouse stock. Exp Gerontol 40:303-314

Harper JM, Durkee SJ, Dysko R, Austad SN, Miller RA (2006a) Genetic modulation of hormone levels and lifespan in hybrids between laboratory and wild-derived mice. J Gerontol Biol Med Sci 61:1019-1029

Harper JM, Leathers CW, Austad SN (2006b) Does caloric restriction extend life in wild mice? Aging Cell 5:441-449

Harper JM, Salmon AB, Leiser SF, Galecki AT, Miller RA (2007) Skin-derived fibroblasts from long-lived species are resistant to some, but not all, lethal stresses and to the mitochondrial inhibitor rotenone. Aging Cell 6:1-13

Hemann MT, Greider CW (2000) Wild-derived inbred mouse strains have short telomeres. Nucleic Acids Res 28: 4474-4478

Hillesheim E, Stearns SC (1992) Correlated responses in life-histroy traits to artificial selection for body weight in fruitflies (Drosophila melanogaster). Evolution 46: $745-752$

Holzenberger M, Dupont J, Ducos B, Leneuve P, Geloen A, Even PC, Cervera P, Le Blouc Y (2003) IGF-1 receptor 
regulates lifespan and resistance to oxidative stress in mice. Nature 421:182-187

Hsu H, Li L, Zhang H, Mountz J (2005) Genetic regulation of thymic involution. Mech Ageing Develop 126:87-97

Hulbert AJ, Faulks SC, Harper JM, Miller RA, Buffenstein R (2006) Extended longevity of wild-derived mice is associated with peroxidation-resistant membranes. Mech Ageing Develop 127:653-657

Hulbert AJ, Pamplona R, Buffenstein R, Buttemer WA (2007) Life and death: metabolic rate, membrane composition, and lifespan of animals. Physiol Rev 87:1175-1213

Hutchinson EW, Rose MR (1991) Quantitative genetics of postponed aging in Drosophila melanogaster. I. Analysis of outbred populations. Genetics 127:719-727

Hutchinson EW, Shaw AJ, Rose MR (1991) Quantitative genetics of postponed aging in Drosophila melanogaster. II. Analysis of selected lines. Genetics 127:729-737

Ingram D, Jucker M (1999) Developing mouse models of aging: a consideration of strain differences in age-related behavioral and neural parameters. Neurobiol Aging 20:137-145

Jansen RC (2003) Studying complex biological systems using multifactorial perturbation. Nat Rev Genetics 4:145-151

Johnson K, Zheng Q, Noben-Trauth K (2006) Strain background effects and genetic modifiers of hearing in mice. Brain Res 1091:79-88

Klebanov S, Astle CM, Roderick TH, Flurkey K, Archer JR, Chen J, Harrison DE (2001) Maximum lifespans in mice are extended by wild strain alleles. Exp Biol Med 226:854-859

Künzl C, Kaiser S, Meier E, Sachser N (2003) Is a wild mammal kept and reared in captivity still a wild animal? Horm Behav 43:187-196

Kunzl C, Sachser N (1999) The behavioral endocrinology of domestication: A comparison between the domestic guinea pig (Cavia apereaf.porcellus) and its wild ancestor, the Cavy (Cavia aperea). Horm Behav 35:28-37

Lambert AJ, Boysen HM, Buckingham JA, Yang T, Podlutsky A, Austad SN, Kunz TH, Buffenstein R, Brand MD (2007) Low rates of hydrogen peroxide production by isolated heart mitochondria associate with long maximum lifespan in vertebrate homeotherms. Aging Cell 6:607-618

Leakey JE, Chen S, Manjgaladze M, Turturro A, Duffy PH, Pipkin JL, Hart RW (1994) Role of glucocorticoids and "caloric stress" in modulating the effects of caloric restriction in rodents. Ann N Y Acad Sci 719:171-194

Lee AT, Cerami A (1992) Role of glycation in aging. Ann N Y Acad Sci 663:63-70

Liang H, Xiong WH, Zhang ZB (2007) Effect of maternal food restriction during gestation on early development of $\mathrm{F} 1$ and F2 offspring in the rat-like hamster (Cricetulus triton). Zoology 110:118-126

Manning EL, Crossland J, Dewey MJ, Van Zant G (2002) Influences of inbreeding and genetics on telomere length in mice. Mamm Genome 13:234-238

Martin-Gronert MS, Ozanne SE (2006) Maternal nutrition during pregnancy and health of the offspring. Biochem Soc Trans 34:779-782

Masoro E (2005) Overview of caloric restriction and ageing. Mech Ageing Develop 126:913-922
Masoro EJ (2007) The role of hormesis in life extension by dietary restriction. Interdiscip Top Gerontol 35:1-17

McCarter R, Mejia W, Ikeno Y, Monnier V, Kewitt K, Gibbs M, McMahan A, Strong R (2007) Plasma glucose and the action of calorie restriction on aging. J Gerontol A Biol Sci Med Sci 62:1059-1070

Melvin RG, Ballard JW (2006) Intraspecific variation in survival and mitochondrial oxidative phosphorylation in wild-caught Drosophila simulans. Aging Cell 5:225-233

Metcalfe NB, Monaghan P (2003) Growth versus lifespan: perspectives from evolutionary ecology. Exp Gerontol 38:935-940

Miller R, Nadon N (2000) Principles of animal use for gerontological research. J Gerontol Biol Med Sci 55: B117-B123

Miller RA, Austad SN, Burke D, Chrisp C, Dysko R, Galecki A, Jackson A, Monnier VM (1999) Exotic mice as models for aging research: polemic and prospectus. Neurobiol Aging 20:217-231

Miller RA, Dysko R, Chrisp C, Seguin R, Linsalata L, Buehner G, Harper JM, Austad S (2000a) Mouse (Mus musculus) stocks derived from tropical islands: new models for genetic analysis of life history traits. J Zool 250:95-104

Miller RA, Chrisp C, Atchley W (2000b) Differential longevity of mouse stocks selected for early life growth trajectory. J Gerontol A Biol Sci Med Sci 55:B455-B461

Miller RA, Harper JM, Dysko R, Durkee SJ, Austad SN (2002a) Longer lifespans and delayed maturation in wildderived mice. Exp Biol Med 227:500-508

Miller RA, Harper JM, Galecki A, Burke D (2002b) Big mice die young: early life body weight predicts longevity in genetically heterogenous mice. Aging Cell 1:22-29

Murakami S (2006) Stress resistance in long-lived mouse models. Exp Gerontol 41:1014-1019

Murray T, Desai K, Cinader B (1993) Age-related changes in hepatic and splenic insulin receptors and serum insulin and glucose levels in inbred mice. Metabolism 42:140-144

Nussey DH, Kruuk LEB, Morris A, Clutton-Brock TH (2007) Environmental conditions in early life influence ageing rates in a wild population of red deer. Current Biol 17: R1000-R1001

Patel AC, Nunez NP, Perkins SN, Barrett JC, Hursting SD (2004) Effects of energy balance on cancer in genetically altered mice. J Nutr 134:3394S-3398S

Patronek GJ, Waters DJ, Glickman LT (1997) Comparative longevity of pet dogs and humans: implications for gerontology research. J Gerontol A Biol Sci Med Sci 52: B171-B178

Reznick D, Buckwalter G, Groff J, Elder D (2001) The evolution of senescence in natural populations of guppies (Poecilia reticulata): a comparative approach. Exp Gerontol 36:791-812

Rikke BA, Yerg JE III, Battaglia ME, Nagy TR, Allison DB, Johnson TE (2003) Strain variation in the response of body temperature to dietary restriction. Mech Ageing Develop 124:663-678

Rikke BA, Yerg JE III, Battaglia ME, Nagy TR, Allison DB, Johnson TE (2004) Quantitative trait loci specifying the response of body temperature to dietary restriction. J Gerontol Biol Sci Med Sci 59:B118-B125 
Roberts RC (1981) Genetic influences on growth and fertility. In: Berry RJ (ed) Biology of the house mouse. Symp Zool Soc London 47:231-251

Roberts A, Pardo-Manuel de Villena F, Wang W, McMillan L, Threadgill D (2007) The polymorphism architecture of mouse genetic resources elucidated using genome-wide resequencing data: implications for QTL discovery and systems genetics. Mamm Genome 18:473-481

Rose MR, Rauser CL, Benford G, Matos M, Mueller LD (2007) Hamilton's forces of natural selection after forty years. Evolution 61:1265-1276

Rubio MA, Davalos AR, Campisi J (2004) Telomere length mediates the effects of telomerase on the cellular response to genotoxic stress. Exp Cell Res 298:17-27

Stuermer IW, Tittman C, Schilling C, Blottner S (2006) Reproduction of wild Mongolian gerbils bred in the laboratory with respect to generation and season 1. Morphological changes and fertility lifespan. Anim Sci 82:377-387
Van Voorhies W, Fuchs J, Thomas S (2005) The longevity of Caenorhabitis elegans in soil. Biol Lett 1: 247-249

Weindruch R, Walford RL (1988) The retardation of aging and disease by dietary restriction. Thomas, Springfield

Wislon AJ, Nussey DH, Pemberton JM, Pilkington JG, Morris A, Pelletier F, Clutton-Brock TH, Kruuk LE (2007) Evidence for a genetic basis of aging in two wild vertebrate populations. Curr Biol 17:2136-2142

Wong A, Brown R (2007) Age-related changes in visual acuity, learning and memory in $\mathrm{C} 57 \mathrm{BL} / 6 \mathrm{~J}$ and $\mathrm{DBA} / 2 \mathrm{~J}$ mice. Neurobiol Aging 28:1577-1593

Yoshiki A, Moriwaki K (2006) Mouse phenome research: implications of genetic background. ILAR J 47:94102

Zheng Q, Johnson K, Erway L (1999) Assessment of hearing in 80 inbred strains of mice by ABR threshold analyses. Hearing Res 130:94-107 